\title{
Güneybatı Anadolu'dan Yeni Bir Paleoekolojik Değerlendirme: Karataş Gölü ve Çevresinin Geç Holosen Paleovejetasyon Değişimleri ve İklim ile İlişkileri
}

\author{
A New Paleoecological Assessment of Southwest Anatolia: Late Holocene Paleovejetation \\ Changes and Relationships with Lake Karatas and its Surroundings
}

\author{
Çetin ŞENKUL ${ }^{1}$ (i), Emine KALIPÇI ${ }^{2}$ (])
}

${ }^{1}$ Süleyman Demirel Üniversitesi, Fen Edebiyat Fakültesi, Coğrafya, Isparta, Türkiye

${ }^{2}$ Süleyman Demirel Üniversitesi, Sosyal Bilimler Enstitüsü, Coğrafya, Isparta, Türkiye

ORCID: Ç.Ş. 0000-0002-7641-1143; E.K. 0000-0001-8005-4049

\section{ÖZ}

Bu çalışma, Güneybatı Anadolu'da Burdur Depresyonu'nun güneybatısında (Tefenni Ovası) yer alan Karataş Gölü'nde yapılmıştır. Çalışmanın temel amacı, Karataş Gölü ve çevresinin 2000 yıl öncesinden günümüze paleovejetasyon değişimini ve bu değişimler üzerinde etkili olan faktörleri belirlemektir. Bu amaç doğrultusunda Karataş Gölü'den temin edilen toplam uzunluğu $255 \mathrm{~cm}$ (GÖ 1890 kal. ${ }^{14} \mathrm{C}$ ) olan sediman karotu üzerinde fosil polen analizleri gerçekleştirilmiş ve elde edilen veriler Tilia 2.0.41 programında diyagram haline getirilmiştir. Fosil polen diyagramına göre arboreal polen (AP) içerisinde Pinus sp., Juniperus sp. ve Quercus sp. (evergreen), nonarboreal polen (NAP) içerisinde ise Chenopodiaceae, Asteraceae, Lactuaceae ve Poaceae önemli türler olmuştur. Bu türlerin zamansal olarak değişimleri göl çevresinde etkili olan yerel vejetasyon yapısını ortaya koymaktadır. Genel olarak kalibre (kal.) GÖ 1460-1150, kal. GÖ 840-680, kal. GÖ 680-480 arasında Abies sp., ve Cedrus libani soğuk dönemler olduğunu göstermektedir. Tüm diyagram içerisinde insan etkilerinin en yoğun olduğu dönem kal. GÖ 840-30 olarak belirlenmiştir. AP içerisinde Olea europaea, Vitis sp., Fraxinus sp.; NAP içerisinde ise Polygonum aviculare, Plantago lanceolata, Centaurea solstitialis'in diyagramda en yoğun olduğu dönemdir. Sonuç olarak, fosil polen analiz metotlarına bağlı olarak, iklim değişikliği ve insan etkisi sonucunda paleovejetasyon yapısını oluşturan bireysel bitki türleri çeşitliliği ve orman ilerlemesi/gerilemesi kapsamında değerlendirilmiş̧ir.

Anahtar kelimeler: Fosil polen, Paleovejetasyon ve iklim değişikliği, Karataş Gölü

\section{ABSTRACT}

This study was carried out in Lake Karataş which is located at the site of Burdur Depression in the southwestern Anatolia (Tefenni Plain). The main aim of the study is to determine the changes of paleovegetation and the factors that effect these changes from 2000 cal. BP years ago to Lake Karataş and its surroundings. For this purpose, fossil pollen analysis methods were applied on sediment core with a total length of $255 \mathrm{~cm}$. The data obtained were diagrammed in the Tilia 2. 0. 41 program. Pinus sp., Juniperus sp. and Quercus sp. (evergreen) in arboreal pollen (AP) and Chenopodiaceae, Asteraceae, Lactuaceae and Poaceae in nonarboreal pollen (NAP) are important species that forming the vegetation. The temporal changes of these species reveal the local vegetation structure which is effective around the lake. Generally Abies sp., Cedrus libani and Quercus sp. (evergreen) indicate that $1460-1150$ cal. BP, 840-680 cal. BP and 680-480 cal. BP are cold periods. In the whole diagram, the peak period of human impact was determined as 840-30 cal. BP. Olea europaea, Vitis sp. Fraxinus sp. in AP and Polygonum aviculare, Plantago lanceolata, Centaurea solstitialis in NAP corresponds to the peak period in the diagram. As a result, depending on the methods of analysis of fossil pollen, as a result of climate change and human impact, the variety of individual plant species constituting the paleovegetation structure and forest progression / regression were evaluated.

Keywords: Fossil pollen, paleovegetation and climate change, Lake Karataş

Bu makale çalışması SYL-2018-6908 nolu Bilimsel Araştırma Projeleri tarafından desteklenen Yüksek Lisans Tezi tarafından desteklenmiştir.

Başvuru/Submitted: 19.02.2019 • Revizyon Talebi/Revision Requested: 27.03.2019 • Son Revizyon/Last Revision Received: 31.05 .2019 • Kabul/Accepted: $12.06 .2019 \cdot$ Online Yayın/Published Online: 29.06.2019 


\section{EXTENDED ABSTRACT}

This study was carried out in Lake Karataş which is located at the site of Burdur Depression in the southwestern Anatolia (Tefenni Plain). The main aim of the study was to determine the last $\sim 2000$ cal. BP years of paleovegetation change and the factors that affecting this changes at Lake Karataş and its surroundings. For this aim, drilling was performed from the most convenient point where depth of water and sediman accumulation is sufficient with no flow and contaminete in Lake Karataş. As a result of the field work, sediment core which is total length of $255 \mathrm{~cm}$ was obtained. Fossil pollen analysis methods were applied on a total of 34 samples with nearly $8 \mathrm{~cm}$ interval on the sediment core. The data obtained from pollen analysis were identified in the light microscope. The data obtained were diagrammed in Tilia 2.0.41 program. The samples taken from $138 \mathrm{~cm}$ and $253 \mathrm{~cm}$ on the sediment core of Lake Karataş were dated. According to the results of ${ }^{14} \mathrm{C}$ aging analysis, $1384 \pm 25 \mathrm{BP}$ and $254 \mathrm{~cm}$ and $1922 \pm 27 \mathrm{BP}$ years of age were obtained.

Depending on the changes occurring on the diagram are divided 2 main zones and 6 subzones. KTG 18 Zone 1 covers 882-1889 cal. BP and KTG Zone 2 comprise 5-882 cal. BP. During the Hot Climate Period of Rome, 1400 Cold Climate Period, Medieval Hot Climate Period and Little Ice Age Climate Period changes in the paleovegetation structure of Lake Karataş and its vicinity were determined. Pinus sp., Juniperus sp. and Quercus (evergreen) sp.' in AP (arboreal pollen) and Chenopodiaceae, Asteraceae, Lactuaceae and Poaceae in NAP (nonarboreal pollen) are important species that forming the vegetation structure. The temporal changes of these species reveal the local vegetation structure which is effective around the lake. In Zone 1, the AP ratio was $61.6 \%$ in 1885 cal BP and $78.9 \%$ in 915 cal. BP at the end of the zone. One of the important points in this zone is that Fraxinus sp. reached its highest level with $15 \%$ in 1850 cal. BP. The most represented species in herbaceous vegetation are Chenopodiaceae, Lactuaceae and Asteraceae. AP ratio in zone 2 was $76.6 \%$ in $840 \mathrm{BP}$ and $83.2 \%$ at the end of zone. In the AP, Olea europaea, Vitis sp., Fraxinus sp. and in NAP, Polygonum aviculare, Plantago lanceolata, Centaurea solstitialis that peaked in the diagram (840-30 BP) corresponds to the highest human impact period.

Between 2000 and 1400 cal. BP, when in the Hot Climate Period of Rome which is characterized by the increase of evaporation and drought in the Eastern Mediterranean, the rate of decrease in NAP is observed in the 1890s cal. BP.

The presence of the Cedrus libani and Quercus sp. (evergreen) showing the humid climatic condition was increased between 1340 and1145 cal. BP in the 1400 Cold Climate Period (1450-1050 cal. BP), where there is a transition towards to cooler, humid and variable climatic conditions in Europe. The dominance of Chenopodiaceae, Asteraceae and Lactuaceae in NAP reflects the local vegetation of Lake Karataş and its surroundings.

Increased solar radiation causes The Archaic Oscillation index to reached positive values in the Medieval Warm Climate Period (1050-650 cal. BP) which is characterized by an increase in temperatures, the ratio of Quercus sp. (evergreen)and Cedrus libani showed increase. While Chenopodiaceae showed a decrease Poaceae, Asteraceae and Artemisia sp. ratios showed a steady increasing trend that the local vegetation had found a distribution area around the lake. The existence of Polygonum aviculare, Plantago lanceolata and Centaurea solstitialis which indicate grazing activities and the existence of Olea europaea, Juglans sp, Brassicaceae and Cerealia type which indicate agricultural activities are important evidence of human impact around the lake.

Between 650 and 100 cal. BP, when Little Ice Age Climate Period Eastern Mediterranean was more humid and cold weather conditions. The increase in Abies sp, Cedrus libani and Quercus sp. (evergreen) at the Spörer Minimum Period and the Maunder Minimum Period indicates the presence of the cold period. Chenopodiaceae, Lactuaceae, Poaceae and Artemisia sp. formed dominant species in NAP. The total presence of Olea europaea, Vitis sp, Fraxinus sp. and Juglans sp at Little Ice Age corresponds to the highest agricultural production.

Consequently, depending on the methods of fossil pollen analysis, climate change and human impact on paleovegetation were determined with in the scope of progression/regression in forest and changes in individual plant species diversity. 


\section{GÍRIŞ}

Anadolu'nun bitki taksonları için Asya, Avrupa ve Afrika arasında bir köprü oluşturması, insanın doğal ortam üzerindeki baskısının uzun dönemli etkilerini üzerinde barındırması Anadolu'yu paleoekolojik çalışmalar için ön plana çıkarmaktadır (McNeil, 1992; Eastwood vd., 1998, 1999; Leroy vd., 2002; Caner ve Algan, 2002; Mudie vd., 2002; Bolle, 2003; Oğuz, 2004; Mudie vd., 2007; Magyari vd., 2007; Kaniewski, 2007; Bakker, 2013). Nitekim şimdiye kadar gerçekleştirilmiş çok sayıdaki paleoekolojik çalışmalar ile Anadolu'daki paleovejetasyon koşullarının rekonstrüksiyonu, orman ilerlemesi/ gerilemesi, bireysel bitki tür çeşitliliği ve iklimsel değişimlere dair önemli bir bilgi birikimi elde edilmiştir. Bu bilgilerin yanı sıra tarımsal faaliyetler, otlatma, orman açma gibi insan etkili ortamsal değişimler hakkında da önemli altlıklar bulunmaktadır (Butzer, 2005; Kaniewski vd., 2007; Şenkul, 2014; Bradshaw vd., 2015; Miebach, 2016). Bu değişimlerin ortaya konulabilmesi için yapılan paleoekolojik araştırmalar içerisinde en çok faydalanılan yöntemlerden biri polen analizleridir (Behre, 1990; Eastwood, 1997; Birks ve Birks, 2000; Brewer vd., 2002; England, 2006; Seppä, 2007; Şenkul, 2014). Anadolu genelinde vejetasyon yapısının zamansal olarak nasıl değiştiğinin iyi anlaşılması gelecekteki vejetasyon yapısının öngörülmesinde önemli bir değere sahiptir (Woodbridge vd., 2017). Bu kapsamda Anadolu genelinde vejetasyon özelliklerinin ve vejetasyonla ilişkili değişimlerin ortaya konulduğu pek çok çalışma gerçekleştirilmiştir (van Zeist vd., 1975; Bottema ve Woldring, 1984; van Zeist ve Bottema, 1991; Kaniewski vd., 2007; Şenkul vd., 2018a, 2018b; Şenkul ve Doğan, 2018; Karlığlu Kılıç vd., 2018). Bu çalışmalar ise Anadolu'nun belirli bölgelerinde (Güneybatı Anadolu, Marmara Bölgesi’nin güney kesimleri, Kapadokya Yöresi) yoğunlaşmıştır. $\mathrm{Bu}$ bölgeler içerisinde özellikle Güneybatı Anadolu'da birçok çalışma yapılmıştır (van Zeist vd., 1975; Bottema ve Woldring, 1984; Vermore vd., 2002; Vermore, 2004; Kaniewskivd., 2007). Birbirinden bağımsızolarak gerçekleştirilen bu çalışmalarda Güneybatı Anadolu'nun vejetasyon yapısı, temelde iklim özellikleri ve ortam üzerindeki insan etkileri (ormansızlaşma, aşırı otlatma) nedeniyle şekillendiği ve değiştiği belirlenmiştir (Kaniewski vd., 2007, Butzer, 2005). Ancak Güneybatı Anadolu geneli için 2000 yıl öncesinden günümüze kadar olan zaman dilimi, insanın vejetasyon değişimi üzerindeki artan etkilerini tespit etmek ve bu süreçteki iklim değişimlerinin rölünü belirlemek karmaşık olabilmektedir.

$\mathrm{Bu}$ çalışma yeni paleoekolojik araştırmalar ile Güneybatı Anadolu'daki vejetasyon, iklim değişikliği ve insan etkisi arasındaki ilişkiselliği kurgulamak adına Karataş Gölü'nde gerçekleştirilmiştir. 2000 y1l öncesinden günümüze Karataş Gölü ve yakın çevresinin paleovejetasyon değişimlerinin ve bu değişimler üzerinde etkili olan faktörlerin (insan etkisi ve iklim) ortaya konulması çalışmanın temel amacını oluşturmaktadır. $\mathrm{Bu}$ amaç doğrultusunda Karataş Gölü'nden yüksek çözünürlüklü fosil polen verisi elde edilerek göl çevresinde meydana gelen değişimler değerlendirilmiştir.

\section{CCALIȘMA ALANI}

Karataş Gölü (1043 m) Burdur depresyonunun güneybatısında Tefenni Ovası üzerinde yer almaktadır. Karataş Gölü batıda Eşler Dağı (2267 m) ve Bozdağ (1834 m), doğuda Katrancık Dağı (2328 m), kuzeyde Beşparmak Dağları (2028 m) ile çevrelenmiştir. Ayrıca göl çevresinde Kartal Tepesi (1749 m), Koruklu Tepe (1767) ve Pınar Tepe $(2214 \mathrm{~m})$ gibi önemli yükseltiler bulunmaktadır. Karataş Gölü’nün beslenme kaynaklarını havza geneline düşen yağışlar, sürekli ve mevsimsel akarsular ve kaynak suları oluşturmaktadır (Sungur, 1978; Ardel, 1952-1953).

KD-GB yönlü olan Fethiye-Burdur fay zonu üzerinde yer alan Karataş Gölü tektonik kökenlidir. Gölün konumlandığı Tefenni Ovası genellikle Kuvaterner yaşlı alüvyal depolardan oluşmaktadır. Karataş Gölü Tefenni Ovası'ndan marn, gre ve konglomeralardan oluşan Neojen tepeleriyle ayrılmaktadır (Sungur, 1978; Ardel, 1952-1953). Çalışma alanının batısında yer alan Eşler Dağı'nda Mesozoyik yaşlı peridotitler yayılış göstermektedir (Sungur, 1978). Alanın kuzey ve güneyindeki tepelik alanlar ile doğusundaki Katrancık Dağı genellikle Mesozoyik yaşlı ofiyolitik melanj ve neritik kireç taşlarından oluşmaktadır (Sungur, 1978).

Çalışma alanının güneyden Akdeniz iklimi ile kuzeyden İç Anadolu'nun karasal etkilerinin karşılaşma sahasında yer almasına bağlı olarak iklim, jeomorfolojik özellikler farklı yetişme ortamlarının oluşmasını sağlamıştır (Yayıntaş, 1989; Avc1, 1990; 1996a; 1996b). Burdur (1950-2015) istasyonunda Ocak ayı ortalama sicaklık $2,7{ }^{\circ} \mathrm{C}$, Temmuz ayı sicaklık ortalamas $24,7{ }^{\circ} \mathrm{C}$, yıllık ortalama sicaklık ise $13,3{ }^{\circ} \mathrm{C}$ 'dir (Tablo, 1). Tefenni (1963-2015) istasyonunda Ocak ayı ortalama sicaklık $1,2{ }^{\circ} \mathrm{C}$, Temmuz ayı sicaklık ortalamas $23,3{ }^{\circ} \mathrm{C}$, yıllık ortalama sicaklık $14{ }^{\circ} \mathrm{C}$ 'dir (Tablo 1). Burdur istasyonunda Ocak ayı toplam ortalama yağış $55,8 \mathrm{~mm}$, Temmuz ayı toplam ortalama yağış 12,1 mm'dir (Tablo 1). Tefenni istasyonunda Ocak ayı toplam ortalama yağış $63,1 \mathrm{~mm}$, Temmuz ayı toplam ortalama yağış 14 mm'dir (Meteoroloji Genel Müdürlüğü). Her iki istasyonda da yağışların oranı yaz mevsimine göre kış mevsiminde fazladır ve yağışların önemli bir kısmı ilkbahar 
mevsiminde meydana gelmektedir. Karataş Gölü'nün yer aldığı alçak alanlar Thornthwaite Yağış Etkinlik Sınıfı'na göre kurakyarı nemli (C1) alanlar, Thornthwaite Sıcaklık Tesiri Sınıfları'na göre 1. dereceden mezotermal (B’1) olarak belirlenmiştir. Bu alçak alanları doğudan ve batıdan sınırlayan dağlık alanlarda ise Thornthwaite Yağış Etkinlik Sınıfı'na göre yarı nemli (C2), Thornthwaite Sicaklık Tesiri Sinıfları'na 2. dereceden mezotermal (B’2) olarak belirlenmiştir (Yılmaz ve Çiçek, 2016).

Gölün kıyı kesimlerinde Juncus heldreichianus, J. maritimus, J. gerardi, Eleocharis palustris, Scirpoides holoschoenus, Scorzonera parviflora, Alopecurus arundinaceus, Veronica anagallis-aquatica, Bolboschoenus maritimus, Schoenoplectus
Tablo 1: Burdur (1950-2015) ile Tefenni (1963-2015) sıcaklık ve yağış verileri ( Meteoroloji Genel Müdürlüğü).

Table 1: Temperature and precipitation data in Burdur (1950-2015) and Tefenni (1963-2015) (General Directorate of Meteorology).

\begin{tabular}{lcc}
\hline & Burdur & Tefenni \\
\hline Yıllık Ortalama Sıcaklık $\left({ }^{\circ} \mathrm{C}\right)$ & 13,3 & 11,8 \\
Ortalama Sıcaklık Ocak $\left({ }^{\circ} \mathrm{C}\right)$ & 2,7 & 1,2 \\
Ortalama Sıcaklık Temmuz $\left({ }^{\circ} \mathrm{C}\right)$ & 24,7 & 23,3 \\
Toplam Yağış Ortalaması $(\mathrm{mm})$ & 426,9 & 430,4 \\
T. Yağış Ortalaması Ocak $(\mathrm{mm})$ & 55,8 & 63,1 \\
T. Yağış Ortalaması Temmuz $(\mathrm{mm})$ & 12,1 & 14 \\
\hline
\end{tabular}

lacustris gibi sulak alan türlerinin oluşturduğu topluluklar yer almaktadır (Özçelik vd., 2014). Çalışma alanı içerisinde orman örtüsünün tahrip edildiği alanlarda maki formasyonlarından
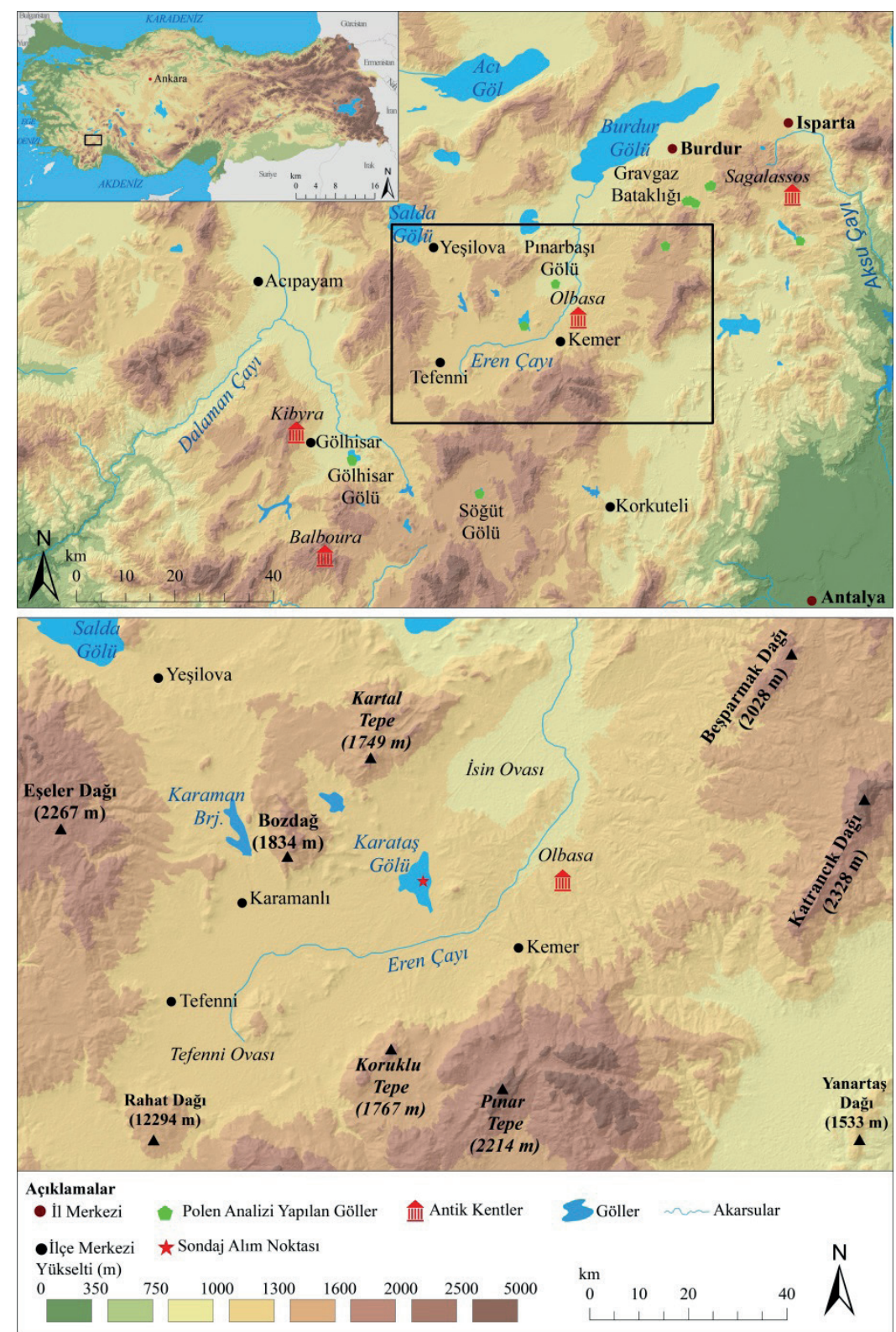

Şekil 1: Çalışma alanı lokasyon haritası.

Figure 1: Study area location map. 
Berberis vulgaris, Juniperus oxycedrus, Styrax officinalis, Daphne sericea, D. gnidioides, Phillyrea latifolia ve Quercus coccifera ortaya çıkmaktadır (Yayıntaş, 1989; Avc1, 1990; Güner ve Ekim, 2014; Özçelik vd., 2014). Çalışma alanı içerisinde bulunan Katrancık Dağı ve Eşler Dağı'nda Juniperus excelsa, J. foetidissima, Pinus brutia, P. nigra, Cedrus libani, Abies cilicica, orman örtüsünü oluşturan bitki türleridir (Sungur, 1978; Avc1, 1990; Avc1, 1995: Şenkul, 2011). Ayrıca Paliurus aculeatus, Crataegus monogyna, bitki türleri yayılış göstermektedir.

\section{YÖNTEM}

\subsection{Fosil Polen Verilerinin Elde Edilmesi}

\subsubsection{Arazi Çalışması}

Karataş Gölü'nde sondaj alımının gerçekleştirileceği alan; su derinliğinin yeterli, sediman birikiminin fazla, akıntının, kirlenme ve oksidasyonun olmadığı en uygun nokta olarak belirlenmiştir. Sediman karotlarının alınmasında yüzey sediman örneği için Glew corer sondaj alım ekipmanı kullanılmıştır. Ardından öncelikle Livingstone ( $5 \mathrm{~cm}$ çaplı) ve sonrasında da Russian core (3 cm çaplı) örnek alıcısı kullanılarak (göl tabanına ait sediman alımınındaki zorluktan dolayı) toplamda $255 \mathrm{~cm}$ uzunluğunda sediman karotu 2018 yılı Temmuz ayında elde edilmiştir.

\subsubsection{Laboratuvar Çalışması}

Sediman karotları üzerinde yaklaşık her $8 \mathrm{~cm}$ 'de bir olmak üzere toplam 34 sediman örneği alınmıştır. Alınan her bir örnek için palinoloji laboratuvarında fosil polen analizleri klasik yöntem (Erdtman, 1943; Faegri ve Iversen, 1975; Moore vd., 1991; Seppa, 2007) uygulanarak polen görünümünü arttırmak amacıyla polen dışındaki yabancı maddeler örneklerden uzaklaştırılmıştır. Laboratuvar aşamasında uygulanan klasik yöntem sonrası örnekler teşhis edilmeye ve sayılmaya hazır hale getirilmiştir. Örnekler ışık mikroskobunda, $\mathrm{x} 40$ ve x100 mercekleri kullanılarak teşhis edilmiştir. Sayılacak polen miktarını belirlemek amacıyla polen temsil testi uygulanmış ve toplamda 350 kara polenin sayılacağ belirlenmiştir. Ardından alınan her bir örnek için 350 kara poleni sayılarak toplamda 11.900 kara poleni sayılmış, bu verilerin Tilia 2.0.41 programında fosil polen diyagramı oluşturulmuş (Şekil 3) ve cluster analizleri (Grimm, 2015) yapılmıştır.

\subsection{Radyokarbon/AMS Tarihlendirme Verilerinin Elde Edilmesi}

Karataş Gölü'ne ait sediman karotu üzerinden $138 \mathrm{~cm}$ ve 254 cm'den alınan örnekler TÜBİTAK Marmara Araştırma Merkezi laboratuvarında tarihlendirilmiştir. Sediman örnekleri üzerinde asitte çözünmeyen toplam karbon ile Karbon $14\left({ }^{14} \mathrm{C}\right)$ analizi uygulanmıştır.

\section{BULGULAR}

\subsection{Tarihlendirme Bulguları ve Yaş Derinlik Modeli}

${ }^{14} \mathrm{C}$ yaşlandırma analizi sonucunda Karataş Gölü’ne (KTG) ait sediman karotu üzerinde $138 \mathrm{~cm}$ 'de GÖ $1384 \pm 25$ ve 253 cm'de GÖ $1922 \pm 27$ yaşları elde edilmiştir (Şekil 2). Bu yaş

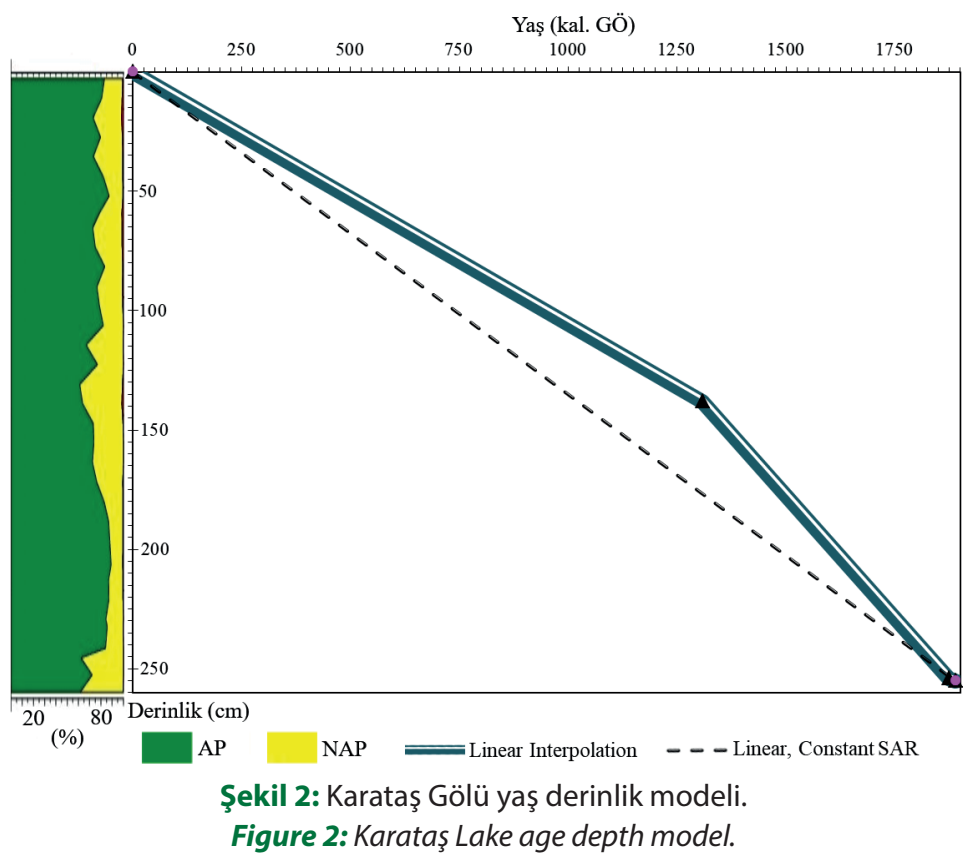


Tablo 2: Karataş Gölü kalibre edilmiş yaş tarihleri.

Table 2: Karataş Lake calibrated age dates.

\begin{tabular}{lccccc}
\hline Örnek Lab. No. & Derinlik & ${ }^{14}$ C GÖ & ${ }^{14} \mathbf{C}$ kal. GÖ & \multicolumn{2}{c}{ Kalibrasyona Göre } \\
\hline & & & & \multicolumn{2}{c}{ Orta Nokta } \\
\cline { 4 - 6 } & & & & kal. MS & kal.GÖ \\
\hline KTG -138 & 138 & $1384 \pm 25$ & $1338-1279$ kal. GÖ & 642 & 1308 \\
KTG-25 & 253 & $1922 \pm 27$ & $1930-1818$ kal. GÖ & 76 & 1874 \\
\hline
\end{tabular}

verileri OxCal. 4.3 programı kullanılarak IntCal13 ile kalibre edilmiştir (Tablo 2) (Ramsey, 2017). Kalibre yaş verileri üzerinden Karataş Gölü için yaş derinlik profili çizilmiştir.

Kal. ${ }^{14} \mathrm{C}$ yaşları referans alınarak tüm sediman karotunun zamansal kronolojisi linear interpolasyon yöntemi ile hesaplanmıştır. Buna göre sediman örneklerinin taban yaşı (255 cm) GÖ kal. 1889 olarak belirlenmiştir. Zamansal kronoloji Tilia 2.0.41 programı ile polen diyagramına entegre edilerek değişimler zamansal çerçevede değerlendirilmiştir.

\section{2. Fosil Polen Bulguları}

Fosil polen yüzde diyagramında 2 ana (KTG (Karataş Gölü 18) Zon 1, KTG Zon 2) ve 6 alt zon KTG Zon 1a, KTG Zon 1b, KTG Zon 1c, KTG Zon 1a, KTG Zon 2a, KTG Zon 2b, KTG Zon 2c) belirlenmiş̧ir (Şekil 3).

\subsubsection{KTG Zon 1 (93-255 cm; kal. GÖ 882-1889)}

Zon başlangıcında kal. GÖ 1885 yılında AP oranı \% 61,6 iken zon bitiminde kal. GÖ 915 yılında \% 78,9’dur.

Pinus sp. kal. GÖ 1885-1535 arasında artış, kal. GÖ 15351220 arasında azalış ve kal. GÖ 1220-915 arasında tekrar artış göstermiş̧ir. Quercus sp. (evergreen) oranı \% 0,9-2,6 oranında temsil edilmiştir ve önemli değişimler yaşanmamıştır. Juniperus sp. ikincil ağaç türünü oluşturmuş ve Pinus sp.'un azalış gösterdiği yıllarda artış göstermiştir. kal. GÖ 1885-1735 arası Fraxinus sp. 'un en yoğun olduğu dönemdir. Juglans sp. kal. GÖ 1380-1220 arasında \% 0,3-0,6 oranında görülmüştür. Polygonum aviculare ve Centaurea solstitialis kal. GÖ 1420-1220 arasında $\%$ 0,3-1,4 arasinda temsil edilmektedir. Cerealia sp. zon geçişlerinde nispeten iyi oranda görülmüştür.

Otsu türler içerisinde Chenopodiaceae'nin artış ve azalış gösterdiği yıllar Pinus sp. ile benzerlik göstermiştir. Otsu vejetasyon içerisinde en önemli türler ise Lactuaceae ve Asteraceae'dır. Artemisia sp. zon içerisinde kal. GÖ 1295-915 yılları arasında yer almıştır.
KTG Zon 1a (213-255 cm; kal. GÖ 1677-1889): Zon başlangıcında kal. GÖ 1885 yılında AP oranı \% 61,6 iken zon bitiminde kal. GÖ 1695 yılında \% 87,2'dir. Zon içerisinde AP oranı genel olarak artış, NAP oranı ise genel olarak azalış eğilimi göstermiştir.

$\mathrm{Bu}$ zon içerisinde Pinus sp. oranında önemli değişimler meydana gelmiştir. Pinus sp. zon başlangıcında \% 35,5 iken, zon bitiminde kal. GÖ 1695 yılında \% 63 değeri ile en yüksek AP türüdür Juniperus sp. en yüksek değere sahip ikinci AP türüdür. Zon içerisinde genel olarak bir artış eğilimi göstermiş ve en yüksek değerine (\% 22,5) zon bitiminde ulaşmıştır. Quercus sp. (evergreen) oran1 \% 0,6- \% 2,6, Quercus sp. (deciduous) oranı ise \% 0,3- \% 1,7 arasında değişmektedir. Fraxinus sp. hem zon içerisinde hem tüm diyagram içerisinde \% 15 ile en yüksek seviyesine kal. GÖ 1850 yılında ulaşmıştır. Ardından sürekli azalış eğilimi göstermiş ve zon bitiminde \% 0,3 değerine düşmüştür. Olea europaea ve Juglans sp. \% 0,3 değerine sahiptir.

En yüksek orana sahip otsu türler Chenopodiaceae \% 25,3, Poaceae \% 12,7 ve Lactuaceae \% 2,1 oranında görülmüştür. Otlatma göstergesi olan Centaurea solstitialis \% 0,6, Polygonum aviculare \% 1,7 değerindedir. Tahıl içerisinde ise Cerealia sp. \% 0,3 ile düşük oranda temsil edilmiştir.

KTG Zon $1 b$ (143-213 cm; kal. GÖ 1333-1677): Zon başlangıcında kal. GÖ 1625 yılında AP oranı \% 89,2 ile tüm diyagram içerisinde en yüksek orana sahiptir. AP oranı zon içerisinde sürekli artış, NAP oranı ise azalış eğilimindedir.

Kal. GÖ 1540 yılında Pinus sp. \% 84,9 oranı tüm diyagramda en yüksek seviyesine ulaşmasına rağmen zon içerisinde sürekli azalmıştır. Juniperus sp. zon 1a'dan zon 1b'ye geçişte \% 20,8 oranında ani bir azalış göstermiştir. Quercus sp. (evergreen) \% 1,7 oranında, Quercus sp. (deciduous) ise sadece zon bitiminde $\%$ 0,6 oranında görülmüştür. Juglans sp., Fraxinus sp. ve Olea europaea ise \%0,3 değerindedir. Vitis sp. ilk defa bu zon içerisinde kal. GÖ 1420 yllında \%0,2 gibi düşük bir oranda görülmüş̧ür. 
Otsu türler içerisinde Chenopodiaceae oranında genel olarak artış yaşanmış ve zon bitiminde \% 19,1 değerine sahiptir. Asteraceae ve Lactuaceae \% 2,5 oranında, Polygonum aviculare ve Centaurea solstitialis \% 1,1 oranında, Plantago lanceolata \% 0,5 oranında temsil edilmiştir. Tahıl içerisinde ise Cerealia sp. \% 0,6 ile düşük oranda temsil edilmiştir.

KTG Zon 1c (93-143 cm; kal. GÖ 882-1333): Zon başlangıcında kal. GÖ 1295 yılında AP oranı \%64 iken zon bitiminde kal. GÖ 915 yılında AP oranı \% 78,9’dur.

Odunsu türler içerisinde en yüksek orana sahip türler Pinus sp. (\% 75,8) ve Juniperus sp. (\% 5,1)’tur. Quercus sp. (deciduous) zon bitiminde \% 2,5 oranına ulaşmıştır. Ekili ağaç türlerinden Vitis sp. \% 0,9, Olea europaea \% 0,8, Juglans sp. \% 0,6, Fraxinus sp. $\% 0,3$ değerine sahiptir.

Chenopodiaceae'nın sahip olduğu oran (\% 28,2) diğer zonlar içerisinde en yüksek seviyeye ulaşmıştır. Artemisia sp. ilk defa bu zon içerisinde görülmüş ve zon bitiminde kal. GÖ 915 yılında $\% 2$ değerine ulaşmıştır. Asteraceae ve Poaceae zon içerisinde genel olarak artış eğilimi göstermiştir. Centaurea solstitialis \% 1,4, Polygonum aviculare \% 1,1 ve Plantago lanceolata \% 0,6 oranında temsil edilmiştir. Cerealia sp. oranında zon 1b'den zon 1c’ye geçiş sırasında \% 1,1 artış yaşanmıştır.

KTG Zon 2 (0,5-93 cm; kal. GÖ 5-882): AP oranı kal. GÖ
840 yılında \% 76,6 oranında görülürken zon bitiminde \% 83,2 oranında görülmüştür.

Pinus sp. ve Juniperus sp. en önemli AP türlerini oluşturmaktadır. Quercus sp. (evergreen) zon başlangıcında \% 0,6 iken zon bitiminde \% 7,8 oranında temsil edilmiştir. Juniperus sp. tüm diyagram içerisinde kal. GÖ 110 yılında \% 43,3 ile en yüksek değere ulaşmıştır. Olea europaea (\% 2,5), Fraxinus sp. (\% 1,7) Juglans sp. (\% 0,8)'1n en iyi bu zon içerisinde temsil edilmesi insan etkisinin günümüze doğru arttığını göstermektedir.

Otsu türler içerisinde Chenopodiaceace'nin oranı zon 1'e göre azalış göstermiştir. Lactuaceae, Asteraceae, Poaceae, Artemisia sp. otsu vejetasyonu oluşturan diğer önemli türlerdir. Polygonum aviculare $(\%$ 1,4), Plantago lanceolata $(\% 4,3)$ ve Centaurea solstitialis $(\% 1,7)$ oranında görülmüştür. Tahıl türleri içerisinde Secale cereale \% 0,3, Hordeum sp. \% 0,6, Cerealia type $\% 1,6$ oranında temsil edilmiştir.

KTG Zon 2a (47-93 cm; kal. GÖ 446-882): Bu zonda Pinus sp. genel olarak artış-azalış eğilimi göstermiştir. Tüm diyagram içerisinde kal. GÖ 610 yilında Quercus sp. (deciduous) $(\% 5,9)$ oranı ilk defa Quercus sp. (evergreen) (\% 4,9) oranından yüksektir. Juniperus sp. \% 3,1, Cedrus libani \% 1,7 oranına sahiptir. Fraxinus sp. ve Vitis sp. \% 1,7, Olea europaea \% 1,1, Juglans sp. \% 0,6, Pistacia sp. \% 0,5 değerindedir.

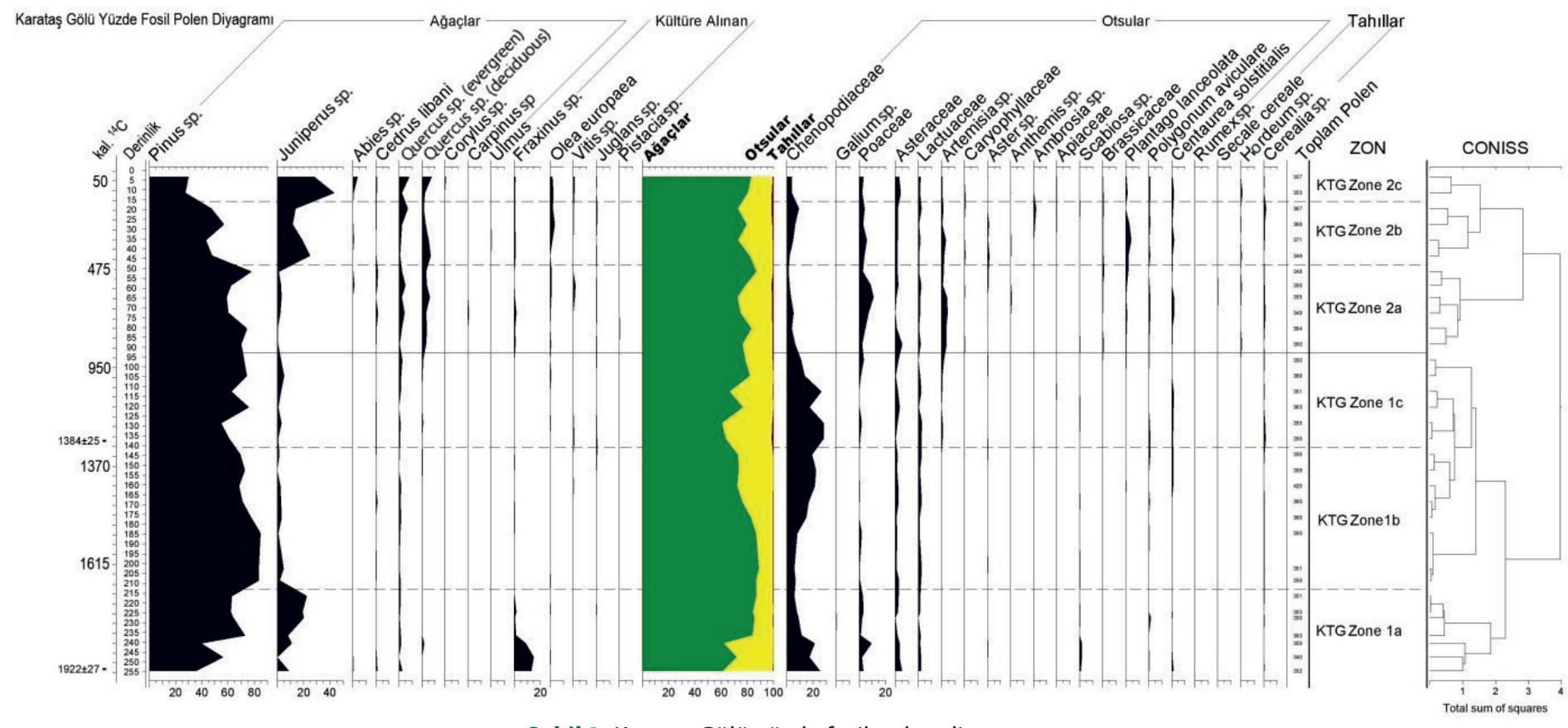

Şekil 3: Karataş Gölü yüzde fosil polen diyagramı.

Figure 3: Percent fossil pollen diagram of Karatas Lake. 


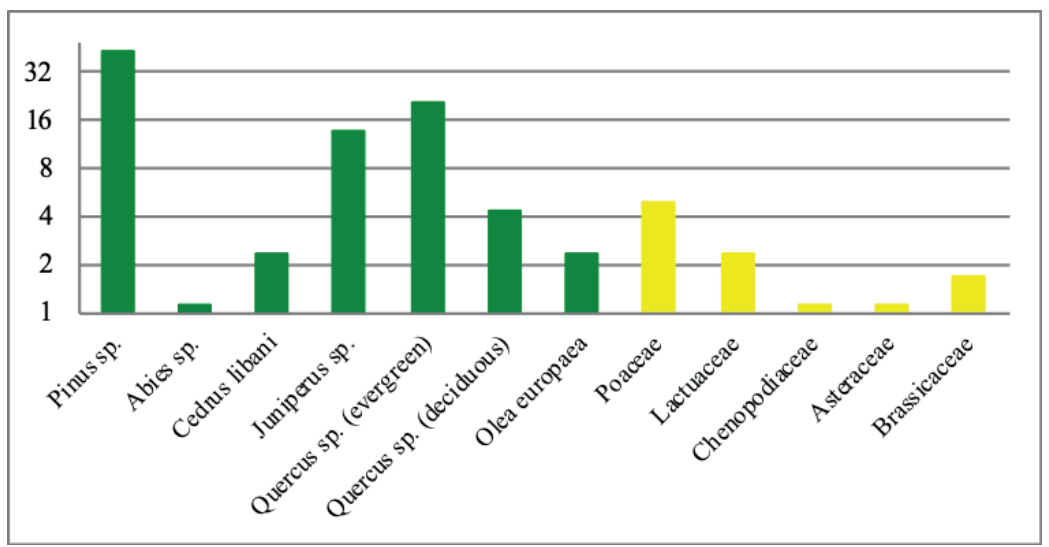

Şekil 4: Yüzey sediman örneğine ait güncel polen yüzdesi.

Figure 4: Modern pollen percentage of surface sediment sample.

Otsu türler arasında tür çeşitliliğin en fazla olduğu zondur. Poaceae tüm diyagram içerisinde $\% 11$ oranı ile en yüksek değerine sahip olmuştur. Chenopodiaceae \% 6,3 Artemisia sp. \% 4,9 oranında temsil edilmiştir. Polygonum aviculare ve Plantago lanceolata $\% 1,1$, Centaurea solstitialis \% 1,7, Rumex sp. ise \% 0,3 oranına sahiptir. Tahıl içerisinde Secale cereale \% 0,3, Hordeum sp. \% 0,9, Cerealia $\mathrm{sp}$. ise \% 1,1 olarak görülmüştür.

KTG Zon 2b (15-47 cm; kal. GÖ 142-446): Pinus sp. değeri zon 2a'dan zon 2b'ye geçişte \% 30 azalış göstermiştir. Juniperus sp. kal. GÖ 335 yılında en yüksek seviyesine \% 19,1 değeri ile ulaşmıştır. Pinus sp., Quercus sp. (evergreen), Quercus sp. (deciduous) ve Juniperus sp. AP oranının belirleyici türleri olmuştur. Cedrus libani, Betula sp., Abies sp., Carpinus sp., Olea europaea, Fraxinus sp., Juglans sp. zon içerisinde görülen diğer türlerdir.

NAP içerisinde tür çeşitliliğin en fazla olduğu zondur. Kal. GÖ 185 yılında Chenopodiaceae \% 9,3 ve kal. GÖ 355 yılında Poaceae \% 5,9 ile en yüksek orana sahiptir. Lactuaceae \% 2,5 ile 0,5 arasında değişim göstermiştir. Asteraceae zon başlangıcında \% 5,1 iken zon bitimine doğru azalış eğilimi göstermiştir. Artemisia sp. \% 3,5, Polygonum aviculare ve Centaurea solstitialis \% 1,1, Plantago lanceolata \% 4,3, oranına sahiptir. Cerealia sp. \% 1,6 ile tüm diyagram içerisindeki en yüksek değerine $(\% 1,6)$ kal. GÖ 185 yılında ulaşmıştır.

KTG Zone 2c (0,5-15 cm; kal. GÖ 5-142): Tüm diyagram içerisinde AP oranında kal. GÖ 110 yılında Juniperus sp. değeri ilk defa \% 43,3 ile Pinus sp. değerinden yüksektir. Pinus sp. ise bu zon içerisinde \% 30 değerine sahiptir. Quercus sp. (evergreen) \% 7,8 ve Quercus sp. (deciduous) \% 7,5 değerindedir. İndikatör türler içerisinde yer alan Olea europaea \% 2,5, Fraxinus sp. \% 1,1 ve Juglans sp. ise \% 0,6 oranında temsil edilmiştir.
Otsu türler içerisinde en yüksek orana sahip türler Chenopodiaceae $(\% 3,9)$ ve Poaceae $(\% 3,4)$ dir. Lactuaceae, Asteraceae, Artemisia sp. zon içerisinde görülen diğer otsu türlerdir. Plantago lanceolata \% 2,7, Centaurea solstitialis \% 1,7, Polygonum aviculare \% 1,1 oranına sahip indikatör türler içerisindedir. Tahıllar içerisinde Hordeum sp. \% 1,1 Cerealia sp. $\%$ o,6 oranına sahiptir.

\subsection{Yüzey Sediman Örneği Bulguları}

Yüzey sediman örneği içerisinde toplam AP oranı \% 86,9'dir. AP oranı içerisinde en yüksek değer \% 46,2 ile Pinus sp., \% 20,6 ile Quercus sp.'a (evergreen) ve \% 13,7 ile Juniperus sp.'ye aittir (Şekil 4). İndikatör türler arasında yer alan Olea europaea ise \% 2,3 oranında görülmüştür. NAP oranı içerisinde en yüksek değere sahip türler sırasıyla \% 4,9 Poaceae, \% 2,3 Lactuaceae, $\% 1,7$ Brassicaeae'dir.

\section{TARTIŞMA}

Kal. GÖ 2000-1400 Yılları Arası Paleovejetasyon Değişimi: Bu dönem içerisinde Doğu Akdeniz'de buharlaşma ve kuraklık koşullarında artış, yağış koşullarında ise azalış yaşanmıştır (Tainter, 2007; Mccormıck vd., 2012; Haldon vd., 2014). Roma Sıcak Dönemi'ne karşılık gelen bu iklim koşulları Anadolu'yu da etkisi altına almıştır. Tecer ve Nar Gölü’nde yapılan çalışmalarda yaz kuraklığının arttığını ve Orta Anadolu'da kış yağışlarının azaldığını göstermektedir (Jones vd., 2006; Kuzucuoğlu vd., 2011). İznik Gölü'nden elde edilen bulgulara kal. GÖ 2200-1900 yılları daha serin fakat kurak iklim koşulları yaşanırken kal. GÖ 1900’den itibaren ise nemli dönem etkisini göstermiş ve göl seviyesinde yükselmeler gözlenmiştir (Ülgen vd., 2014). Güneybatı Anadolu'da yer alan Gravgaz Bataklığ1 ve Bereket Havzası'ndan elde edilen bulgulara göre kal. GÖ 1700- 
1300 bölgede kurak koşulların varlığına rağmen yoğun tarıma faydalı olan nispeten nemli koşullarla karakterize olduğu belirtilmektedir (Bakker vd., 2013). Yapılan çalışmalarda ortaya çıkan farklılıklar Roma Sıcak İklim Dönemi'nde Anadolu'da bölgesel farklılıkların olduğunu ortaya koymaktadır.

Karataş Gölü ve çevresinde kal. GÖ 1885'lerde AP oranındaki azalış ile NAP oranındaki artış kurak dönemin yaşandığını göstermektedir. Kal. GÖ 1885 'lerde orman vejetasyonu içerisinde Pinus sp. ve Juniperus sp. oranları düşük olmasına rağmen kal. GÖ 1655 'lerde artış yaşanmış ve toplam AP oranı artmıştır. Orman varlığının önemli bir göstergesi olan Pinus sp. oranında meydana gelen azalışa bağlı olarak Juniperus sp. ikincil bir orman elemanı olarak ortaya çıkmaktadır. AP oranının azalış gösterdiği yıllarda açık vejetasyon içerisinde step özellikli Asteraceae familyasina ait türler (Bottema ve Woldring, 1990) artış göstermiştir. kal. GÖ 1885-1420 yılları arası diyagramda kültüre alınan türler içerisinde yiyecek ve tıbbi ilaç yapımında kullanılan Fraxinus sp. (Vermore vd., 2000)'un varlığı sahada yoğun olarak görülmüştür. Akdeniz iklimi ve karasal iklimin karşılaşma sahasında yer almasına bağlı olarak kültüre alınan ve tarımı yapılan türler arasında Olea europaea ve Juglans sp., Fraxinus sp.'a oranla daha az temsil edilmiştir. Diyagramda Centaurea solstitialis ve Plantago lanceolata'nın varlığ insan aktivitelerinin (otlatma vb.) vejetasyon yapısı üzerindeki etkilerini (Bottema ve Woldring, 1990; Eastwood, 1997) göstermektedir.

\section{Kal. GÖ 1450-1050 Yılları Arası Paleovejetasyon Değişimi:} Bu dönem Bond-1 olarak adlandırılan iklim dönemine karşılık gelmektedir. Avrupa'da daha serin, nemli ve değişken iklim koşullarına doğru bir geçiş yaşanmıştır (Bond vd., 1997; 2001). $\mathrm{Bu}$ soğuk iklim döneminin etkileri Anadolu üzerinde de hissedilmiştir. Tarihi kaynaklarda kal. GÖ 1210-1205 arası dönemde Anadolu'da kış aylarında aşırı soğuklarından dolayı İstanbul Boğazı'nın donduğu belirtilmektedir (Yavuz vd., 2007). Kal. GÖ 1350-1150 yılları arasında İznik Gölü’ndeki bulgulara görekuraklık yaşanırken (Ülgen vd., 2014), kal. GÖ 1450-1150 Tecer Gölü ve Nar Gölü’ndeki bulgulara göre (Jones vd., 2006; Kuzucuoğlu vd., 2011) nemli dönemler yaşanmıştır. Güneybatı özelinde incelendiğinde ise Gravgaz Bataklığı'nda elde edilen verilere göre kal. GÖ 1700-1300 arası dönemde yerel nemlilik koşulları artış göstermiştir (Bakker vd., 2013). Daha kurak dönemin başlangıcı Gravgaz Bataklığı'nda kal. GÖ 1200'lerde başladığı düşünülmektedir (Bakker vd., 2013).

Küresel etkilerinin pek çok farklı alanda görüldüğü bu iklim döneminin etkileri Karataş Gölü ve çevresinde nispeten daha az görülmüştür. Diyagramda kal. GÖ 1340-1145 arasında nispeten nemli iklim koşullarını gösteren Cedrus libani ve Quercus sp. (evergreen)'un varlığı soğuk iklim koşullarının yaşandığını göstermektedir. NAP içerisinde Chenopodiaceae, Asteraceae ve Lactuaceae familyalarının baskın olması Karataş Gölü ve çevresinin yerel vejetasyonunu yansıtmaktadır. Chenopodiaceae oranı genel olarak artış göstermiş kal. GÖ 1295-1070 arasında en yoğun olarak görülmektedir. Fraxinus sp. kal. GÖ 1700'lere göre daha düşük oranlarda temsil edilirken Juglans sp. hemen hemen aynı oranlarda görülmüştür. Polygonum avicularae ve Centaurea solstitialis' in varlı̆̆ insanın vejetasyon üzerindeki etkisinin devam ettiğini göstermektedir.

Kal. GÖ 1050-650 Yılları Arası Paleovejetasyon Değişimi: Bu dönem Ortaçağ Sicak İklim Dönemi koşullarının yaşandığ 1 döneme karşılık gelmektedir. Bu iklim döneminde artan güneş radyasyonu Arkaik Salınım indisinin pozitif değerlere ulaşmasına neden olarak sıcaklığın küresel ölçekte artmasına neden olmuştur (Lamb, 1965; Perry ve Hsu, 2000; Fairbridge, 2009). Bu iklim döneminin Anadolu'da yansıması yapılan çalışmalardan elde edilen bulgulara göre kal. GÖ 1150-700 arasında İznik Gölü’nde (Ülgen vd., 2014) ve kal. GÖ 930-795 arasında Aktaş Gölü’nde (Karlığlu Kılıç vd., 2018) iklimin daha nemli koşullarda yaşandığını gösterirken kal. GÖ 1000-950 arasında Tecer Gölü'nde iklim koşullarının kuru ve yaz sıcaklıklarında bir artış yaşandığını göstermiştir. Anadolu'da ağaç halkaları üzerinde yapılan bir çalışmada kal. GÖ 850-780 arasında nemli koşulların hakim olduğu söylenmiştir (Touchan vd., 2007). Sicak ve kuru iklim koşulları Gravgaz Bataklı̆̆ı ve çevresinde kal. GÖ 800'ün ilk yıllarından itibaren, Bereket Havzası'nda ise kal. GÖ 800'lerin ortalarından itibaren etkili olmuştur (Bakker vd., 2013).

Karataş Gölü ve çevresinde bu iklim döneminde AP oranlarının genel olarak yüksek olduğu görülmüştür. Orman vejetasyonu içerisinde kal. GÖ 840-690 Quercus sp. (evergreen) ve Cedrus libani artış göstermiş̧ir. Fakat gölün bulunduğu depresyon sahası göz önünde bulundurulduğunda otsu vejetasyon yapısı içerisinde Chenopodiaceae azalış gösterirken Poaceae, Asteraceae ve Artemisia sp. oranlarının artı̧ eğiliminde olması göl çevresinde yerel vejetasyonun yayılış alanı bulduğunu göstermektedir. Vejetasyon yapısı içerisinde Olea europaea, Juglans sp., Brassicaceae ve Cerealia type'in varlığı tarımsal faaliyetlerin yapıldığını işaret etmektedir. Polygonum aviculare, Plantago lanceolata ve Centaurea solstitialis'in varlığı göl çevresinde hayvancılık faaliyetlerinin yapıldığını yansıtmaktadır (Bottema ve Woldring, 1990).

Kal. GÖ 650-100 Yılları Arası Paleovejetasyon Değişimi: Bu y1llar arasında düşük güneş aktivitesi ve güneş lekesine (Eddy, 1976; Spörer, 1887; Lean vd., 1995; Lu, 2018) bağlı olarak Doğu 
Akdeniz daha nemli ve soğuk koşullar yaşanmıştır (Barriendos, 1997; Rodrigo vd., 2000; Xoplaki vd., 2001). Küçük Buzul Çağı olarak bilinen bu dönem içerisinde iklim değişkenlik göstererek Spörer Minimum (kal. GÖ 550-440) (Cho, 2014), Maunder Minimum (kal. GÖ 305-235) (Luterbacher vd., 2001), Dalton Minimum (kal. GÖ 150-90) (Luterbacher vd., 2001; Cho, 2014) gibi daha soğuk dönemler yaşanmıştır. Küresel ölçekte yaşanan bu soğuk iklim döneminin etkileri Anadolu özelinde bölgeden bölgeye değişkenlik göstermiş ve farklı zamanlarda hissedilmiş̧ir. Anadolu'da kal. GÖ 800-100 arası dönemde İstanbul Boğazı'nın tamamen veya kısmen donduğu tarihi kayıtlarda belirtilmiştir (Yavuz vd., 2007). Bizans toprakları kal. GÖ 675-500 yılları arasında aşırı soğuklar, şiddetli kışlar ve sağanak gibi iklim olaylarıyla karşılaşmıştır (Haldon vd., 2014). Osmanlı topraklarında kal. GÖ 405 şiddetli soğuk ve kar yağışı ile yolların kapandığını ve karayollarının harap edildiğini, hayvanların soğuktan öldüğünü gösteren tarihi kayıtlar bulunmaktadır (White, 2008, 2011). Yapılan çalışmalarda elde edilen bulgulara göre Tecer Gölü'nde kal. GÖ 800-500, İznik Gölü'nde kal. GÖ 700-300 arasında kurak iklim koşulları artış göstermiştir (Ülgen vd., 2014). Gravgaz Bataklığı ve çevresinde kal. GÖ 500 yılından itibaren artan nemli iklim koşulları kal. GÖ 200 yıllarında devam etmiştir (Bakker vd., 2013). Ağaç halkaları ise kal. GÖ 490-480 ve kal. GÖ 250-190 yıllarında nemli koşulların yaşandığını göstermektedir (Touchan vd., 2007).

Spörer Minimum Dönemi'nde kal. GÖ 555-490 arasında Abies sp., Cedrus libani'ninvarlığı soğuk dönemin varlığına işaret etmektedir. Küçük Buzul Çağı içerisinde maksimum koşulların yaşandığı Maunder Minimum Dönemi'nde Pinus sp., Juniperus sp., Abies sp. azalış, Ouercus sp. (evergreen) artış göstermiştir. Maunder Minimum Dönemi'nde Plantago lanceolata ve Centaurea solstitialis en yüksek oranına ulaşmıştır. Bu soğuk iklim döneminin son aşaması olan Dalton Minimum'da ise AP oranında düşüş yaşanmıştır. Chenopodiaceae, Lactuaceae, Poaceae ve Artemisia sp. NAP içerisinde baskın türleri oluşturmuştur. Küçük Buzul Çağı Olea europaea, Vitis sp., Fraxinus sp. ve Juglans sp.'in toplam varlığ tarımsal üretimin en yüksek olduğu döneme karşıllk gelmektedir. Orman vejetasyonunu oluşturan türlerin yanında tarımı yapılan türlerde yaşanan değişimler vejetasyon yapısının iklim ile birlikte insan etkisi ile de değiştiğini göstermektedir (Tablo 5).

\section{SONUÇ}

Bu çalışma, fosil polen analizine dayalı olarak Karataş Gölü ve yakın çevresinde $\sim 2000$ yıl öncesinden günümüze paleovejetasyon değişimini ortaya koymaktadır. Küresel iklim dönemlerinin Anadolu üzerindeki yansımaları daha önce yapılan çalışmalar (Jones vd., 2006; Kuzucuoğlu vd., 2011; Bakker vd., 2013; Ülgen vd., 2014) ile belirlenerek iklim koşullarının vejetasyon yapısı üzerindeki etkileri belirlenmiştir. Böylece Güneybatı Anadolu'nun 2000 yıl öncesinden günümüze paleovejetasyon değişimini belirlenmesi adına yeni bir paleoekolojik veri kaydı oluşturulmuştur.

Kal. GÖ 2000-1400'lerde Anadolu'da var olan bölgesel farklılıklar Karataş Gölü ve çevresinde de etkili olmuştur. Kal. GÖ 1885'lerde AP oranında artış, kal. GÖ 1500'lerde ise azalış yaşanmıştır. AP oranı içerisinde kültüre alınan türlerin tespit edilmesi insan etkisinin varlığını kanıtlamaktadır. Sonuç olarak iklim koşulları ile birlikte insan aktivitelerinin süresi, şiddeti ve niteliği vejetasyon yapısı üzerinde değişimlere neden olmuştur.

Karataş Gölü ve çevresinde kal. GÖ 1890-1300 yılları arasında hayvancılık ve tarımsal faaliyetlerin yapıldığı belirlenmiştir. Bu yıllar arasında Fraxinus sp. en çok görülen tür olarak tespit edilmiştir. Olea europaea ve Juglans sp. ise daha düşük oranda temsil edilmiştir. İkincil indikatörlerden Centaurea solstitialis, Polygonum aviculare ve Plantago lanceolata çalışma alanında daha çok etkili olmuştur.

Kal. GÖ 1200'lerde; Ortaçağ Sıcak İklim Dönemi içerisinde kal. GÖ 800'lerde başladığı düşünülen daha kurak dönem Karataş Gölü ve çevresinde etkili olmuştur. NAP içerisinde Chenopodiaceae, Asteraceae ve Lactuaceae familyalarının baskın olması yerel vejetasyon içerisinde kurak iklim koşullarını yansıtmaktadır. Bu dönem içerisinde görülen türler sahada insan etkisinin devam ettiğini göstermektedir. Tarımsal faaliyetlerin yanında kal. GÖ 915-690 yılları arasında Polygonum aviculare, Plantago lanceolata ve Centaurea solstitialis'in varlığ 1 göl çevresinde hayvancılık faaliyetlerinin yapıldığını yansıtmaktadır.

Spörer Minimum ve Maunder Minimum Dönemi'nde Abies sp., Cedrus libani, Juniperus sp., ve Quercus sp. (evergreen)'un artış göstermesi vejetasyon yapısının iklim koşullarına uyum sağladığını göstermektedir. Kal. GÖ 840-30'da birincil indikatör türlerde Olea europaea, Vitis sp., Fraxinus sp. ve Juglans sp.; ikincil indikatör türlerde Polygonum aviculare, Plantago lanceolata, Centaurea solstitialis 'in en yüksek oranına ulaşması ve süreklilik göstermesi insan etkisinin en yoğun olduğu dönem olarak değerlendirilmiştir.

\section{KAYNAKLAR}

Akurgal, E. (2014). Anadolu uygarlıkları. Ankara: Phoenix Yayınevi. Ardel, A. (1952-53). Göller Bölgesi'nde morfolojik müşahadeler II (Burdur depresyonu ve çevresi). Coğrafya Enstitüsü Dergisi,2, 63-86. 
Avcı, M. (1990). Göller Yöresi batı kesiminin bitki coğrafyası. (Doktora Tezi). İstanbul Üniversitesi Sosyal Bilimler Enstitüsü, İstanbul. TÜBESS üzerinden elde edildi. (Tez no: 12784)

Avc1, M. (1995). Plant communities and their distribution on the western part of the Lakes District. Review of the Department of Geography University of İstanbul, 47-72,

Avcı, M. (1996a). Göller Yöresi batı kesiminde iklim özellikleri ile bitki örtüsü arasındaki ilişkiler. İstanbul Üniversitesi Edebiyat Fakültesi Coğrafya Bölümü Coğrafya Dergisi, 4, 143-215.

Avcı, M. (1996b). Göller Yöresi batı kesiminde bitki toplulukları ve dağılışları. İstanbul Üniversitesi Edebiyat Fakültesi Coğrafya Bölümü Coğrafya Dergisi, 4, 227-264.

Bakker, J., Paulissen, E., Kaniewski, D., Poblome, J., De Laet, V., Waelkens, M. (2013). Climate, people, fire and vegetation: new insights into vegetation dynamics in the Eastern Mediterranean since the 1st century AD. Climate of the Past, 9, 57-87. https://doi. org/10.5194/cp-9-57-2013

Barriendos, M. (1997). Climatic variations in the Iberian Peninsula during the Late Maunder minimum (AD 1675-1715): An Analysis of Data from Rogation Ceremonies. The Holocene 7, 105-111. https://doi.org/10.1177/095968369700700110

Behre, K. E. (1990). Some refections on anthropogenic indicators and the record of prehistoric occupation phases in pollen diagrams from the Near East. S. Bottema, G. Entjes-Nieborg, ve W. van Zeist içinde, Man's role in the shaping of the Eastern Mediterranean landscape,( s. 219-230), Rotterdam: A. A. Balkema.

Birks, H. H., Birks, H. J. B. (2000). Future uses of pollen analysis must include plant macrofossils. Journal Of Biogeography, 27, 31-35. https://doi.org/10.1046/j.1365-2699.2000.00375.x

Bolle, H. J. (2003). Mediterranean climate: variability and trends. Munich: Springer Regional Climate Studies.

Bond, G., Showers, W., Cheseby, M., Lotti, R., Almasi, P., deMenocal, P., Priore, P., Cullen, H., Hadjas, I., Bonani, G. (1997). A pervasive millennial-scale cycle in North Atlantic Holocene and glacial climates. Science, 278, 1257- 1266. https://doi.org/10.1126/ science.278.5341.1257

Bond, G., Kromer, B., Beer, J., Muscheler, R., Evans, M. N., Showers, W., Hoffman, S., Lotti-Bond, R., Hajdas, I., and Bonani, G. (2001). Persistent solar influence on North Atlantic climate during the Holocene. Science, 294, 2130-2136. https://doi.org/10.1126/ science. 1065680

Bottema, S., Woldring, H. (1984). Late quaternary vegetation and climate of southwestern Turkey Part II. Palaeohistoria, 26, 245 249.

Bottema, S., Woldring, H. (1990). Anthropogenic indicators in the pollen record of the Eastern Mediterranean. Bottema, S., EntjesNieborg, G., Van Zeist, W. İçinde, Man's role in the shaping of the Eastern Mediterranean landscape (s. 231-264), Rotterdam: Balkema.

Bradshaw R. H. W., Jones C. S., Edwards S.J., Hannon G. E. (2015). Forest continuity and conservation value in Western Europe. The
Holocene, 25, 194-202. https://doi.org/10.1177/0959683614556378 Brewer, S., Cheddadi, R., Beaulieu, J. L., Reille, M. ve Data contributors. (2002). The spread of deciduous Quercus throughout Europe since the last glacial period. Forest Ecology and Management, 156, $27-$ 48 .

Butzer, K.W. (2005). Environmental history in the Mediterranean world: cross-disciplinary investigation of cause-andeffect for degradation and soil erosion. Journal of Archaeological Science, 32(12), 1773-1800. https://doi.org/10.1016/j.jas.2005.06.001

Caner, H., Algan, O. (2002). Palynology of sapropelic layers from the Marmara Sea. Marine Geology,190, 35-46. DOI: 10.1016/S00253227(02)00341-9

Cho, J-H. (2014). The Little Ice Age and the coming of the Anthropocene. Asian Review of World Histories, 1(2), 1-16.

Eastwood, W. J. (1997). The Palaeoecological record of Holocene environmental change in Southwest Turkey. ( $\mathrm{PhD}$ thesis), University of Wales.

Eastwood, W. J., Roberts, C. N., Lamb, H. F. (1998). Palaeoecological and archaeological evidence for human occupancy in southwest Turkey: the Beysehir occupation phase. Anatolian Studies, 48, 6986. https://doi.org/10.2307/3643048

Eastwood, W. J., Roberts, C. N., Lamb, H. F., Tibby, J. C. (1999). Holocene environmental change in southwest Turkey: a palaeoecological record of lake and catchment related changes. Quaternary Science Reviews, 18, 671-695.

Eddy, J. A. (1976). The Maunder minimum, Science, 192, 1189-1202. https://www.jstor.org/stable/1742583

England, A. (2006). Late Holocene palaeoecology Of Cappadocia (CentralTurkey): an investigation of annually laminated sediments from Nar Gölü crater lake. ( $\mathrm{PhD}$ thesis). University of Birmingham.

Erdtman, G. (1943). An introduction to pollen analysis. Waltham: Chronica Botanica Company.

Faegri, K., Iversen, J. (1975). Textbook of pollen analysis. (3. Bask1). New York: Hafner Press.

Fairbridge, R. W. (2009). Medieval warm period. Vivien Gornitz içinde, Encylopedia of paleoclimatology and ancient environments. Hollanda: Springer.

Grimm, E. (2015). Tilia Software. Springfield, Illinois State Museum. Güner, A., Ekim, T. (2014). Resimli Türkiye floras1, Cilt 1. İstanbul: Ali Nihat Gökyiğit Vakfı, Flora Araştırmaları Derneği ve Türkiye İş Bankası Kültür Yayınları yayını.

Haldon, J., Roberts, N., Izdebski, A., Fleitmann, D., McCormick, M., Cassis, M., Doonan,O., Eastwood, W., Elton, H., Ladstätter, S., Manning, S., Newhard, J., Nicoll, K., Telelis, I., Xoplaki E. (2014). The climate and environment of Byzantine Anatolia: Integrating science, history, and archaeology. Journal of Inderdisciplinary History, 45(2), 113-161. https://collections.lib.utah.edu/ark:/87278/s66q56ft

Jones, M. D., Roberts, C. N., Leng, M. J., Türkeş, M. (2006). A highresolution late Holocene lake isotope record from Turkey and links to North Atlantic and monsoon climate. Geology, 34(5), 361-364. https://doi.org/10.1130/G22407.1 
Kaniewski, D., De Laet, V., Paulissen, E., Waelkens, M. (2007). Long term effects of human impact on mountenous ecosystems, western Taurus Mountains, Turkey. Journal of Biogeography, 34, 19751997. https://doi.org/10.1111/j.1365-2699.2007.01753.x

Karlığlu, Kılıç N., Caner, H., Erginal A.F., Ersin, S., Selim, H.H., Kaya H. (2018). Environmental changes based on multi-proxy analysis of core sediments in Lake Aktaş, Turkey: Preliminary results. Quaternary International, 486,89-97. https://doi.org/10.1016/j. quaint.2018.02.004

Kofoğlu, S. (2006). Hamidoğulları Beyliği. Ankara: Atatürk Kültür, Dil ve Tarih Yüksek Kurumu Türk Tarih Kurumu Yayınları.

Kuzucuoğlu, C., Dörfler, W., Kunesch, S., Goupille, F. (2011). Mid-to lateHolocene climate change in central Turkey: the Tecer Lake record. Holocene, 21(1), 173-188.https://doi.org/10.1177/0959683610384163

Lamb, H. H. (1965). The early Medival warm epoch and its sequel. Palaeogeography, Palaoclimatology, Palaoecology, 1, 13-37. https://doi.org/10.1016/0031-0182(65)90004-0

Lean, J., Beer, J., Bradley, R. (1995). Reconstructioonf solar irradiance since 1610: Implications for climate change. Geophysical Research Letters, 22(23), 3195-3198.

Leroy, S., Kazanc1, N., İleri, Ö., Kibar, M., Emre, O., McGee, E., Griffiths H.I. (2002). Abrupt environmental changes within a late Holocene lacustrine sequence south of the Marmara Sea (Lake Manyas, N-WTurkey) : possible links with seismic events. Marine Geology, 190, 531-552. DOI: 10.1016/S0025-3227(02)00361-4

Lu, V. A. (2018). XIV. ve XVII. yüzyıllarda iklimsel ve doğal şartların Osmanlı İmparatorluğu'na etkisi. Pesa Uluslararası Sosyal AraştırmalarDergisi, 2 (4), 216-240.https://doi.org/10.25272/j.2149 -8385.2018.4.2.01

Luterbacher, J., Rickli, R., Xoplaki, E., Tinguely, C., Beck, C., Pfister, C., Wanner, H. (2001). The late Maunder minimum (1675-1715) A key period for studying decadal scale climatic change in Europe. Climatic Change, 49, 441-462.

Magyari, E. K., Chapman, J. C., Gaydarska, B., Marinova, E., Deli, T., Huntley, J. P., Allen, J. R. M., Huntley, B. (2007). The "oriental" composition of the Balkan flora: evidence of presence on the Thracian Plain during the Weichselian late-glacial. Journal of biogeography, 35, 865-883. https://doi. org/10.1111/j.1365-2699.2007.01849.x

McCormick, M., Büntgen, U., Cane, M. A., Cook, E. R., Harper, K., Huybers, P., Litt, T., Manning, S. W., Mayewski, P. A., More, A. F. M., Nicolussi ,K., Tegel, W. (2012). Climate change during and after the Roman Empire: Reconstructing the Past from Scientific and Historical Evidence. Journal of Interdisciplinary History, 43(2), 169-220. https://www.dora.lib4ri.ch/wsl/islandora/object/wsl:4354

McNeil, J. R. (1992). The mountains of the Mediterranean world: an environmental history. Cambridge: Cambridge University Press.

Miebach, A., Niestrath, P., Roeser, P., Litt, T. (2016). Impact of climate and humans on the vegetation in northwestern Turkey: palynological insights from Lake Iznik since the Last Glacial. Climate of the Past, 12, 575-593. https://doi.org/10.5194/cp-12-575-2016
Moore, P.D., Webb, J.A. ve Collinson, M.E. (1991). Pollen analysis. (2. Bask1). Oxford: Blackwell Scientific Publications.

Mudie, P.J., Rochon, A., Aksu, A. E. (2002). Pollen stratigraphy of Late Quaternary cores from Marmara Sea: land-sea correlation and paleoclimatic history. Marine Geology, 190, 233-260. https://doi. org/10.1016/S0025-3227(02)00349-3

Mudie, P.J., Marre, F., Aksu, A. E., Hiscott, R. N., Gillespie, H. (2007). Palynological evidence for climatic change, anthropogenic activity and outflow of Black Sea water during the late Pleistocene and Holocene: Centennial- to decadal-scale records from the Black and Marmara Seas. Quaternary International, 167-168, 73-90. https:// doi.org/10.1016/j.quaint.2006.11.009

Oğuz, D. (2004). Remaining tree species from the indigenous vegetation of Ankara. Landscape and Urban Planning, 68, 371-388.

Özçelik, H., Çinbilgel, İ., Muca, B., Koca, A., Tavuç, İ., Bebekli, Ö. (2014). Burdur ili karasal ve iç su ekosistem çeşitliliği, koruma ve izleme çalışmaları. SDU Journal of Science, 9 (2), 12-43. http:// dergipark.gov.tr/download/article-file/116403

Perry, C. A., Hsu K. J. (2000). Geophysical, archaelogical, and historical evidence support a solaroutput model for climate change. Proceedings of the National Academy of Sciences 97, 12433-12438. https://doi.org/10.1073/pnas.230423297

Ramsey, B. C. (2017) . Methods for summarizing radiocarbon datasets. Radiocarbon, 59(2), 1809-1833. https://doi.org/10.1017/RDC.2017.108

Roberts, N. (1990), Human induced landscape change in south and southwest Turkey during the later Holocene, S. Bottema, G. Entjes-Nieborg, ve W. van Zeist içinde, Man's role in the shaping of the Eastern Mediterranean landscape, (s. 53-67), Rotterdam: A. A. Balkema.

Rodrigo, F. S., Esteban-Parra, M. J., Pozo-Vazquez, D., Castro-Diez, Y. (2000). Rainfall variability in southern Spain on decadal to centennial time scales. International Journal of Climatology, 20, 721-32. http://hera.ugr.es/doi/15009464.pdf

Seppä, H. (2007), Pollen analysis principles. Scott A. Elias içinde, Encyclopedia of Quaternary Science, (s. 2486-2497), Amsterdam: Elsevier.

Sungur, K. A. (1978). Burdur, Acıgöl depresyonları ve Tefenni ovasının fiziki coğrafyast. İstanbul: Edebiyat Fakültesi Matbaası.

Spörer, F. W. G. (1887). Über die Periodizität der Sonnenflecken seit dem Jahre 1618, vornehmlich in Bezug auf die heliographische Breite derselben, und Hinweis auf eine erhebliche Störung dieser Periodizität während eines langen Zeitraumes. Vjschr. Astron. Ges., 22, 323-329.

Şenkul, Ç., (2011). Güneybatı Anadolu'nun holosen paleocoğrafyası. (Doktora Tezi). YÖK Ulusal Tez Merkezi veri tabanından elde edildi. Tez No: 296325)

Şenkul, Ç., (2014). Polen analizinin temel prensipleri ve Kuvaterner ortam koşullarının yeniden yapılandırılmasındaki önemi. Türk Bilimsel Derlemeler Dergisi, 7 (1), 33-41.

Şenkul, Ç., Doğan, M. (2018). Fosil ve güncel polen analizleri ışığında Mucur Obruk Gölü çevresinin paleovejetasyon değişimleri. Türk Coğrafya Dergisi, 70, 19-28. 
Şenkul, Ç., Memiş, T., Eastwood, W. J., Doğan, U. (2018a). Mid-to lateHolocene paleovegetation change in vicinity of Lake Tuzla (Kayseri), Central Anatolia, Turkey. Quaternary International, 486, 98-106. https://doi.org/10.1016/j.quaint.2018.05.026

Şenkul, Ç., Ören, A., Doğan, U., Eastwood, W. J. (2018b)., Late Holocene environmental changes in the vicinity of Kültepe (Kayseri), Central Anatolia, Turkey. Quaternary International, 486, 107-115. .https://10.1016/j.quaint.2017.12.044

Tainter, J., Crumley, C. L. (2007). Climate, complexity, and problem solving in the Roman Empire. Robert Costanza, Lisa J. Graumlich, Will Stefen içinde, Sustainability or Collapse? An Integrated History and Future of People on Earth (s. 61-75), Dahlem Workshop Reports.

Touchan, R., Akkemik, Ü ., Hughes, M. K., and Erkan, N.: May-June precipitation reconstruction of southwestern Anatolia, Turkey during the last 900 years from tree rings. Quaternary Research, 68, 196-202. (2007). https://doi.org/10.1016/j.yqres.2007.07.001

Ülgen, U. B., Franz, S. O., Biltekin, D., Çagatay M. N., Roeser, P. A., Doner, L., Thein, J. (2012). Climatic and environmental evolution of Lake Iznik (NW Turkey) over the last $\sim 4700$ years. Quaternary International 274, 88-101.https://doi.org/10.1016/j.quaint.2012.06.016

van Zeist, W., Woldring, H., Stapert, D. (1975). Late Quaternary vegetation and climate of Southwestern Turkey. Palaeohistoria, 17, $55-143$

van Zeist, W., Bottema, S. (1991). Late Quaternary vegetation of the Near East. Beihefte zum Tübinger Atlas Des Vorderen Orients, Dr. Ludwig Reichert Verlag, Wiesbaden.

Vermoere, M., Smets, E., Waelkens, M., Vanhaverbeke, H., Librecht, I., Paulissen, E., and Vanhecke, L. (2000). Late Holocene environmental change and the record of human impact at Gravgaz near Sagalassos, Southwest Turkey. Journal of Archaeological Science, 27, 571-595. https://doi.org/10.1006/jasc.1999.0478

Vermoere, M., Van Thuyne, T., Six, S., Vanhecke, L., Waelkens, M., Paulissen, E., and Smets, E. (2002). Late Holocene local vegetation dynamics in the marsh of Gravgaz (southwest Turkey). Journal of Paleolimnology, 27, 429-451.
Vermoere, M. (2004). Holocene vegetation history in the territory of Sagalassos (Southwest Turkey) A Palynological Approach Studies, Eastern Mediterranean Archaeology-SEMA 6, Brepols Publishers n.v., Turnhout, 1-347.

Wang, T., Surge, D., Walker, K.J. (2013). Seasonal climate change across the Roman Warm Period/Vandal Minimum transition using isotope sclerochronology in archaeological shells and otoliths, southwest Florida, USA. Quaternary International, 308-309, 230241.

White, S. (2008). Ecology, climate, and crisis in the Ottoman Near East, (PhD thesis), Columbia University Graduate School of Arts and Sciences, 1-446.

White, S. (2011). The Climate of rebellion in the early modern Ottoman Empire. Cambridge: Cambridge University Press. https://doi. org/10.1017/CBO9780511844058

Woodbridge, J., Roberts, N., Fyfe, R., (2018). Pan-Mediterranean Holocene vegetation and land-cover dynamics from synthesized pollen data. Journal of Biogeography, 45(9), 1-16. https://doi. org/10.1111/jbi.13379

Xoplaki, E., Maheras, P., and Luterbacher, J. (2001). Variability of climate in meridional Balkans during the periods 1675-1715 and 1780-1830 and its Impact on Human Life. Climatic Change, 48 (4), 581-615.

Yavuz, V., Akçar, N., Schlüchter, C. (2007). The frozen Bosphorus and its paleoclimatic implications based on a summary of the historical data. Yanko-Hombach, V., Gilbert, A.S., Panin, N., Dolukhanov, P.M. içinde, The Black Sea Flood Question: Changes in Coastline, Climate and Human Settlement (s.633-649) Dordrecht: Springer, 633-649. DOI: 10.1007/978-1-4020-5302-3_26

Yayıntaş, A. (1989). Burdur Katrancık (Kestel) Dağ1 flora ve vejetasyonu, TBAG - 615 Numaralı TÜBİTAK Projesi, Bornova, İzmir.

Yılmaz, E., Çiçek, İ. (2016). Türkiye Thornthwaite iklim sınıflandırması. Journal of Human Sciences, 13(3), 3973-3994. doi:10.14687/jhs. v13i3.3994 
